IZA DP No. 5213

\title{
Parental Job Loss and Infant Health
}

Jason Lindo

September 2010 


\title{
Parental Job Loss and Infant Health
}

\author{
Jason Lindo \\ University of Oregon \\ and IZA
}

\section{Discussion Paper No. 5213 \\ September 2010}

\author{
IZA \\ P.O. Box 7240 \\ 53072 Bonn \\ Germany \\ Phone: +49-228-3894-0 \\ Fax: +49-228-3894-180 \\ E-mail: iza@iza.org
}

\begin{abstract}
Any opinions expressed here are those of the author(s) and not those of IZA. Research published in this series may include views on policy, but the institute itself takes no institutional policy positions.

The Institute for the Study of Labor (IZA) in Bonn is a local and virtual international research center and a place of communication between science, politics and business. IZA is an independent nonprofit organization supported by Deutsche Post Foundation. The center is associated with the University of Bonn and offers a stimulating research environment through its international network, workshops and conferences, data service, project support, research visits and doctoral program. IZA engages in (i) original and internationally competitive research in all fields of labor economics, (ii) development of policy concepts, and (iii) dissemination of research results and concepts to the interested public.
\end{abstract}

IZA Discussion Papers often represent preliminary work and are circulated to encourage discussion. Citation of such a paper should account for its provisional character. A revised version may be available directly from the author. 
IZA Discussion Paper No. 5213

September 2010

\section{ABSTRACT}

\section{Parental Job Loss and Infant Health}

Although there exists a large literature documenting various consequences of job loss, this paper is the first to explore the extent to which the health effects of job displacement extend to the children of displaced workers and also the first to consider whether there are any harmful effects for children who are not yet born when the separation occurs. I use detailed work and fertility histories from the Panel Study of Income Dynamics to estimate the effect of parents' job displacements on children's birth weights. These data allow for an identification strategy that essentially compares the outcomes of children born after a displacement to the outcomes of their siblings born before using mother fixed effects. I find that husbands' job losses have significant negative effects on infant health. They reduce birth weights by approximately four and a half percent with suggestive evidence that the effect is concentrated on the lower half of the birth weight distribution.

JEL Classification: $\quad$ I10, J13, J63

Keywords: children, infant health, job loss, displacement

Corresponding author:

Jason Lindo

Department of Economics

1285 University of Oregon

Eugene, OR 97403

USA

E-mail: jlindo@uoregon.edu

\footnotetext{
* I thank Alan Barreca, Alfredo Burlando, Colin Cameron, Nicole Fortin, Hilary Hoynes, Doug Miller, Marianne Page, Heather Royer, Thomas Lemieux, Larry Singell, Mark Stater, Ann Huff Stevens, Joe Stone, Nick Sly, and Glen Waddell along with seminar participants at the UC-Davis and the University of British Columbia and conference participants at the 2010 Economic Demography Workshop, the 2010 NBER Children's Program Meetings, The Economics of Family Policy Conference at Bergen, the 2010 EALE/SOLE World Conference, and the 2010 Western Economic Association Annual Meetings for helpful comments at various stages of this paper.
} 


\section{Introduction}

This work contributes to the growing literature on the impacts of job displacements that, while initially focusing on lost earnings, has more recently documented important consequences for health. ${ }^{1}$ For example, Eliason and Storrie (2009), Rege, Telle, and Votruba (2009), and Sullivan and von Wachter (2009) have found harmful effects on mortality using data from Sweden, Pennsylvania, and Norway, respectively. ${ }^{2}$ Researchers have also analyzed the mental health effects of displacement, finding mixed results. ${ }^{3}$ Although the health effects have been explored in many different settings, the literature has focused primarily on the effects for displaced workers themselves. ${ }^{4}$ This paper is the first to explore the extent to which the health effects extend to the children of displaced workers. Specifically, I estimate the impact of parents' job displacements on birth weights. To deal with the possibility that job displacements might not be exogenous to infant health, I use models with mother fixed effects so that the estimated effects are driven primarily by a comparison of children born after a displacement to their siblings born before.

Although not usually focusing on health, a number of papers have demonstrated that job displacements have important consequences for the entire family. For example, Stephens (2002) shows that women work more following a husbands' job loss to compensate for his lost earnings; Charles and Stephens (2004) show that getting fired increases the probability of divorce; and Lindo (2010) shows that husbands' displacements affect fertility. Moreover, Oreopoulos, Page, and Stevens (2008), Page, Stevens, and Lindo (2009), and Stevens and Schaller (2009) have demonstrated that there are important consequences for children who

\footnotetext{
${ }^{1}$ For examples of the former, see Ruhm (1991), Jacobson, LaLonde, and Sullivan (1993), and Stevens (1997), among many others.

${ }^{2}$ In contrast, Martikainen, Maki, and Jantti (2007) find no effects on mortality using data from Finland.

${ }^{3}$ For example, Browning, Dano, and Heinesen (2006) find no effect with data from Denmark and Kuhn, Lalive, and Zweimueller (2007) find harmful effects with data from Austria.

${ }^{4}$ To my knowledge, the only exception is Salm (2009) who considers also considers the short-run health effects for spouses. Focusing on older workers in the United States, he finds no impacts on either displaced workers themselves or their spouses.
} 
are in the household when a parent is displaced. This paper, however, is the first to consider the impacts on children born following a parent's job loss.

This work is also closely related to Dehejia and Lleras-Muney (2004) who show that birth weights improve during recessions. While they present evidence suggesting that both selection into motherhood and improvements in health-related behaviors play a role, like other analyses of the health effects of local unemployment rates, the identification strategy cannot disentangle the effects of own job displacements from other aspects of recessions. Recent research suggests that this distinction is crucial. Specifically, Sullivan and von Wachter (2009) find that own job displacements increase mortality for U.S. workers, which is in contrast with evidence that mortality improves during recessions (Ruhm 2000).

This paper can also be thought of as providing a window into the relationship between socioeconomic status and health. In general, measures of socioeconomic status are positively related with measures of health. Figure 1 demonstrates that birth weights, the measure of infant health I focus on in this paper, are no exception. ${ }^{5}$ Of course, it is difficult to ascertain to what extent differences in socioeconomic status cause differences in infant health outcomes because there may be characteristics that lead individuals to have both lower socioeconomic status and to have children with poorer health. As argued in Oreopoulos, Page, and Stevens (2008), Page, Stevens, and Lindo (2009), Sullivan and von Wachter (2009), and Lindo (2010), we can learn about the causal effect of income on various outcomes by considering the effects of job displacements which provide a plausibly exogenous shock to household income after controlling for individual fixed effects. As such, this paper offers insight into the causal link between family income and infant health. ${ }^{6}$

\footnotetext{
${ }^{5}$ A large literature demonstrates that birth weights are a good proxy for infant health. Almond, Chay, and Lee (2005), Black, Devereux, and Salvanes (2007), and Royer (2009) show that birth weight is associated with important short-run outcomes including infant mortality and hospital costs. Further, Behrman and Rosenzweig (2004), Black, Devereux, and Salvanes (2007), Johnson and Schoeni (2007), and Oreopoulos, Stabile, Walld, and Roos (2008) show that birth weights are associated with a wide variety of important long-term outcomes such as IQ, education, earnings and adult health.

${ }^{6}$ This paper complements Lindahl (2005) who analyzes the health effects of monetary lottery prizes in
} 
Using data from the Panel Study of Income Dynamics which has detailed information on both employment histories and fertility histories, I find that a husband's displacement reduces the birth weight of subsequent children by approximately four and a half percent, or five ounces. I find suggestive evidence of economically meaningful effects in the lower end of the birth weight distribution. The results are robust to the inclusion of education group trends and industry trends. I also present evidence suggesting that the effect might be driven by impacts on maternal nutrition. ${ }^{7}$

The rest of this paper is organized as follows. Sections 2 and 3 describe the data and empirical strategy. Section 4 presents the results of the empirical analysis while Section 5 discusses the results. Section 6 concludes.

\section{Data}

This paper uses data from the 1968-1997 waves of the Panel Study of Income Dynamics (PSID) including its Childbirth and Adoption History Supplement (CAHS). The PSID is a longitudinal study that began as a nationally representative sample of households in 1968, with an additional oversample of low-income families. The survey has continued to follow these individuals and their children as they form new households. I use data from each of the original samples (and their split-offs) and use PSID weights. ${ }^{8}$ The CAHS includes

Sweden and Burlando (2010) who considers the effect of the income shock generated by a prolonged blackout in Tanzania.

${ }^{7}$ While it is possible to conduct a similar analysis of women's job displacements, in results not shown in this paper, I have found that women's work activity tends to increase substantially above expected levels prior to displacements. This is not too surprising since many women are have weak ties to the labor market and labor market participation is a prerequisite for displacement. Regardless, this finding suggests that women's job displacements are not exogenous and that any analysis of their effects will be challenged to separate the effects of displacement from the effects of unobservables leading to increased work activity. Although the sample sizes in the PSID are not well suited to this approach, a natural solution to this problem would be to focus on a sample of high-tenure women. Because of their strong attachment to the labor market, this type of issue does not present itself in the analysis of men's work activity.

${ }^{8}$ In particular, throughout the analysis, all estimates use children's sample weights in the last year they are observed in the PSID. 
retrospective fertility histories, with children's year and month of birth, for all individuals of childbearing age surveyed in the PSID in 1985 or later. Most importantly, the data include birth weights in ounces for children born in 1985 and later. ${ }^{9}$

In the appendix, Table A1 shows the distribution of birth weights for the children in the sample. One potential concern with the PSID as a source of birth weight information is that it is reported by parents and, thus, subject to recall error. While misreporting cannot be ruled out, it is reassuring that the sample distribution of birth weights is similar to the nationwide distribution in 1990, the median year of birth for the analysis sample.

My definition of displacement follows Stevens (1997) and others who have used the PSID to study the impacts of job loss. Displacements are identified based on the response to a question asking individuals who are not working, and those who began their current job within the last year, "what happened to your previous job?" Throughout most of the analysis, I define an individual as displaced in the previous year if his last job ended due to a plant or business closing or due to being laid off or fired. ${ }^{10}$ Since it is not clear from the survey whether the job loss occurs in the current or previous year, I assume that the displacement occurred in the previous year.

Topel (1990) explains that the survey might miss displacements since the survey question focuses on the last job. That is, we might incorrectly categorize an individual as not displaced if he has had and left another job after his displacement and before he is surveyed. Since this concern is likely greater for the years following 1997 when the PSID changed to a biennial format, data following 1997 are not used. To be consistent, after identifying displacements using 1968-1997 data, I limit the analysis sample to 1968-1996 since displacements identified in 1997 are assumed to have occurred in $1996 .{ }^{11}$ Finally, while one might experience multiple

\footnotetext{
${ }^{9}$ The PSID also has retrospective data on whether or not children born before 1985 were low birth weight. The results shown in this paper do not use this data so that the sample is consistent throughout; however, estimated impacts that make use of this data are very similar to the presented results.

${ }^{10}$ As a robustness check, I test for different effects across the two categories of involuntary job losses.

${ }^{11}$ Another feature of the data usually mentioned in papers using the PSID to consider the effects of
} 
displacements, I consider the year of the first displacement the "displacement year." This is important because it has been shown that initial displacements predict future displacements and, thus, subsequent displacements should not be considered exogenous (Stevens 1997).

Since the PSID began tracking job changes for heads of households beginning with the 1968 survey and the sample of mothers are those having children in 1985 and later, we can potentially observe work histories for many years before a child's birth. This is important to help ensure that children are not incorrectly classified as "not treated" if a displacement occurred several years prior to a child's birth. With clean identification in mind, the analysis sample that I consider consists of mothers married in 1968 or later with at least two children as only these families will contribute to estimates that control for mother fixed effects. In addition, only children born after a mother was first married are considered so that the indicator for being born after a husband's displacement is not necessarily zero.

Because the links between women, their children, and their spouses is a critical component of this exercise, it may be worth mentioning how these links are made for the following analysis. The CAHS data has identifiers that are used to match the children to their mothers. ${ }^{12}$ Women are linked to husbands on the basis of their relationship code in each given year. Women who are cohabiting with a male partner are considered married. ${ }^{13}$ As a result of this approach, it will not necessarily be the case that each displacement event for a given child will correspond to a father's job loss. The job losses will always correspond to those experienced by a mother's partner while they are living together.

displacement is that, unlike subsequent years, the 1968 survey only asks those who began working for their current employer in the last ten years their reason for leaving the last job. As such, those who report a displacement in 1968 tend excluded from analyses since the timing of their displacements cannot be ascertained. Due to the primary years under consideration in this paper, this restriction is benign.

12 Adopted children are not used in any part of the analysis.

${ }^{13}$ While this approach can be motivated for philosophical reasons, it is also motivated by practical concerns when using the PSID because the distinction between married and cohabiting is not made throughout many years of the survey. 


\section{Empirical Strategy}

As a starting point, I estimate a simple model that compares the birth weights of children born following a husband's first displacement to children for whom no such event has taken place. The regression equation is given by:

$$
y_{s m a}=D_{s m a} \delta+X_{s m a} \beta+\alpha_{a}+u_{s m a}
$$

where $y_{s m a}$ is a birth outcome for child $s$ of mother $m$ at age $a, D_{\text {sma }}$ is an indicator variable equal to one if the child is born in the same year the mother has a displaced husband or any

year afterwards, $X_{s m a}$ is a vector of covariates, $\alpha_{a}$ are age fixed effects, and $u_{s m a}$ is a random error term. $\delta$ is the estimated impact of a husband's displacement.

The estimated impact based on equation (1) will only be valid if husbands' displacements are exogenous to birth outcomes. Since this is unlikely, my preferred estimates are based on a model that includes mother fixed effects to control for fixed characteristics of mothers related to both children's birth weights and the probability of having a displaced husband. The resulting regression equation is as follows:

$$
y_{s m a}=D_{s m a} \delta+X_{s m a} \beta+\alpha_{a}+\alpha_{m}+u_{s m a}
$$

where all of the notation is the same as in equation (1) and $\alpha_{m}$ are mother fixed effects. Using this model, the estimated effect of a husband's displacement is identified by the comparison of siblings born before versus those born after a displacement. Mothers who do not ever have a displaced husband, or only have children before or only after a husband's displacement, are included in the analysis to help identify the other parameters. I also estimate models that allow for heterogeneous effects over time, across gender, and across education groups.

This model is very similar to models that have been used to estimate the impact of dis- 
placements on labor market outcomes. That is, it is a difference-in-difference model that controls for individual fixed effects and time fixed effects. An important aspect that distinguishes this analysis from the analysis of labor market outcomes is that post-displacement birth outcomes cannot be measured for all women. For this reason, as with many papers considering the determinants of infant health, a discussion of possible selection bias is in order.

Also using the PSID, Lindo (2010) estimates the effects of husband's job displacements on fertility. Although this analysis reveals significant impacts on the timing of fertility (causing women to have be more likely to have children immediately after a husband's displacement but to be less likely in later years), the overall impact on fertility is small. In the main estimates which control for mother fixed effects, the point estimates indicate a net impact on fertility of -0.10 children with a standard error estimate of 0.12 .

In addition, the inclusion of mother fixed effects will control for many of the most obvious sources of selection bias. For example, one might be concerned that estimated effects will be biased towards finding negative effects if: (1) husbands' displacements are more likely for women who tend to have lower birth weight children; (2) husbands' displacements increase the probability of having children for women who tend to have lower birth weight children; or (3) husbands' displacements reduce the probability of having children for women who tend to have healthier children. However, all of these concerns are addressed by the inclusion of mother fixed effects which control women's baseline tendency to have low birth weight children in addition to all other fixed unobservable characteristics.

With mother fixed effects in the model, in order for the identifying assumption to be violated, it would have to be the case that older siblings born before a job displacement do not serve as a valid counterfactual for children born afterwards. While not impossible, it is rather difficult to come up with stories that would result in such a violation. One example, however, is the idea that women who experience husbands' displacements might have different 
"birth weight trends." If they have flatter positive trends, it would bias the estimates towards finding negative effects. For this reason, I also present estimates that control for education group trends and industry trends as controls. In addition, I demonstrate that children's birth weights do not diverge from their expected levels in the years immediately prior to a husband's displacement.

Finally, I show the estimated effect for children who are born in the year the husband loses his job. Because most of these children will have been conceived prior to the job loss, this is a sample for whom we can be especially confident that selection bias is not of great concern.

\section{Results}

\subsection{Summary Statistics}

Table 1 presents summary statistics for the sample of children. The columns separate the children into those who are born to a mother who never experiences a husband's displacement, children born before their mother has a displaced husband, and children born following the displacement of a mother's husband.

There are important differences in the characteristics of the mothers who experience a husband's displacement (columns 2 and 3) and those who never experience a husband's displacement (column 1). Those who experience a husband's displacement are less educated in addition to marrying and beginning to have children at younger ages. These differences highlight the importance of controlling for mother fixed effects in estimating the impacts of the job displacements.

It is notable that children born to women never experiencing a husband's displacement appear less healthy than children born to women who do experience a husband's displacement. This suggests that there might be no consequences of a husband's displacement for 
birth weights. On the other hand, children born after a job loss have birth weights approximately six ounces lower than children born which suggests that there might in fact be negative consequences. The next section provides a more formal analysis which allows for statistical inference in addition to a focus on within-family variation.

\subsection{Impacts of Husbands' Displacements on Infant Health}

Table 2 presents regression-based estimates of the effect of a husband's job displacement on children's birth weights. All of the estimates include fixed effects for the mother's age at the time of the birth and a cubic in the year. The controls for mothers' ages will control for the likelihood that an older women is more likely to have had a displaced husband while her age might also be related to the birth weight of her children.

Echoing the summary statistics shown in the preceding section, the estimate in the column 1, which does not yet include mother fixed effects, indicates that children born following a husband's displacement have roughly similar birth weights, on average, to children who are not born following a husband's displacement. However, the estimate in column 2, which adds mother fixed effects to the model, indicates that we should not conclude that husbands' job displacements do not affect infant health. This estimate suggests that when we use a more appropriate counterfactual, the children's older siblings who were born before the displacement, we do observe an impact on birth weights. The point estimate, which is significant at the ten percent level, suggests that a husband's displacement reduces subsequent children's birth weights by four percent on average. The point estimate is slightly larger, and statistically significant at the five percent level, when controls for the child's birth order and sex are included in the model (column 3). ${ }^{14}$

Columns 4 and 5 attempt to address the concern that the estimated effects might be bi-

\footnotetext{
${ }^{14}$ I acknowledge that it is not clear that sex should be included as a control since it might be considered an outcome variable. Results are nearly identical when this control variable is omitted.
} 
ased if women experiencing husband's job displacements have different "birth weight trends" from those who do not. Because of limitations of the data, column 4 begins by only including 4 parameters corresponding to separate trends for women with less than a high school education, those with exactly a high school education, those with some college, and those with a college degree. The point estimate is largely unchanged. Column 5 goes a step further, also including trends for the initial industry each woman's husband is observed in (adding approximately thirty additional parameters to the model). Again, the point estimate suggests that a husband's job displacement reduces birth weights by four to five percent.

Table 3 presents estimated effects on the conventional measure of low birth weight, or the probability that a child has a birth weight of less than 88 ounces (2500 grams), using a linear probability model. While the estimates based on the models with mother fixed effects provide suggestive evidence impacts on low birth weight, there is not sufficient power to reject zero.

Although the definition of low birth weight considered in Table 3 is standard, it is rather arbitrary. Further, we might be interested in knowing the impact on the full range of the birth weight distribution. One way of doing so is to estimate the impact on the probability that a child is less than $\mathrm{Z}$ ounces for all possible Z. These estimates, based on the model with the full set of controls, are presented in Figure 2 which summarizes the distributional impact. Again, while the power of these estimates is limited, they collectively suggest that the impact is concentrated primarily below the median birth weight (120 ounces). ${ }^{15}$

\subsection{Tests for Robustness and Heterogeneity}

In this section, I allow the effects of husbands' job displacements to vary with the timing of births, the type of displacement, child gender, and mother's education. Column 1 of Table

\footnotetext{
${ }^{15}$ It is also important to note the economic significance implied by the estimated effects at the very low end of the birth weight distribution. Because the baseline probabilities are so small in that region, the percentage point increases implied by these estimates constitute a substantial effect in percentage terms.
} 
4 interacts an indicator for being being born to a mother who has a displaced husband with the timing of the birth. Specifically, the regression includes indicators for a child being born in the two years prior to a husband's displacement, an indicator for being born in the same year that a husband is displaced, an indicator for a child being born one to four years after a displacement, and an indicator for a child being born five or more years following a husband's displacement. The omitted category includes children born three or more years before a displacement or being born to a mother who never has a displaced husband. These estimates indicate that both children born immediately following a husband's displacement and those born many years later suffer negative consequences of the displacement. As discussed above, the fact that the effects are evident for children born in the year of displacement is encouraging evidence that the effect is not driven by selection.

These results also show that the estimated coefficient on the indicator for being born in the two years prior to a husband's displacement is approximately zero. This finding provides evidence against the possibility that changes in households' unobservables simultaneously drive husbands' displacements and reduced birth weights. ${ }^{16}$ For example, if family turmoil led to husband's job displacements and poorer infant health, we would probably expect the health effects to manifest themselves prior to the husband's job loss.

Column 2 of Table 4 interacts being born following a husband's displacement with the type of displacement. Specifically, I allow the effect of displacements to be different for job losses due to plant and business closures and for job losses due to a husband being laid off or fired. Both point estimates are negative, indicating birth weight reductions of 6.4 and 4.2 percent, respectively, and we cannot reject that they are the same at conventional significance levels. ${ }^{17}$

\footnotetext{
${ }^{16}$ It is worth noting that it would not be completely unexpected if there was an effect preceding the actual event. The displacement literature consistently finds that individuals' earnings begin to deteriorate prior to displacements taking place.

${ }^{17}$ In the appendix, I present a full set of estimates focusing only on job losses due to plant and business closures. This is accomplished by omitting mothers for whom their husband's initial displacement is due to
} 
To the extent to which a child's health at birth can be influenced by behavior during pregnancy, it is possible that a husband's job displacement might have different consequences for male and female children. In particular, parents expecting boys might exert more effort to mitigate the negative effects of displacement if there is a preference for boys. Column 3 of Table 4 explores the extent to which there are heterogeneous effects across genders. The point estimates suggest that there are harmful effects for children of both genders. The estimated average effect for females is indeed larger than the estimated effect for male children $(6.0 \%$ and significant at the five percent level versus $3.1 \%$ and insignificant at conventional levels) which is consistent with a preference for boys but the estimates are not significantly different from one another.

Column 4 of Table 4 shows the estimated the effects interacted with mothers' levels of education. In particular, the treatment effect is interacted with an indicator variable taking a one if the mother has a high school education or less and it is also interacted with an indicator variable taking a one if the mother has more than a high school education. While both point estimates are negative, they suggest that the impact is greater for women with higher levels of education. This result is perhaps surprising. After all, we would think that lower socioeconomic status households suffering a negative income shock would be more likely to be thrust into poverty as a result. In the next section, I present results that speak to this issue by considering several potential mechanisms that might be behind the effects of husbands' displacements and infant health.

\subsection{Potential Mechanisms}

Table 5 explores the differences in circumstances at birth for children born following a father's displacement relative to their siblings born before. The results are based on the same

being laid off or fired. The estimates are broadly consistent with the main estimates although standard error estimates are fairly large. 
estimation strategy that was used to estimate the effects on birth weights - in addition to an indicator variable taking a one if a child is born following a displacement, the model includes the full set of controls for mother fixed effects, mother's age, year, child gender, birth order, education group trends, and industry trends.

Panel A considers the average effect among all children. Consistent with a vast literature on the earnings losses resulting from job displacement, column 1 indicates that husbands' earnings are approximately 22 percent lower in the year prior to birth for children born following a displacement while column 2 implies that the effect on family income is 17 percent. $^{18}$ Also consistent with this literature, columns 3 and 4 indicate reduced work activity on the part of husbands although the estimates are not statistically significant.

Because the data does not allow for enough power to reject zero, the rest of the results in columns 5 through 10 are best cast as providing suggestive evidence of the mechanisms at work in order to provide hypotheses that merit consideration for future research. Columns 5 and 6 indicate that women work more actively in the year prior to their child's birth following a husband's job displacement, with a greater response on the extensive margin. ${ }^{19}$ This finding suggests that work-induced stress may be a potential factor linking husband's displacements to reduced birth weights. ${ }^{20}$ The estimate in column 7 indicates husband's displacements reduce pre-birth food expenditures by 20 percent. Given overwhelming evidence on the importance of maternal nutrition (Bitler and Currie 2004; Almond and Mazumder 2008; Hoynes, Page, and Stevens 2009, Almond, Hoynes, and Schanzenbach forthcoming), this offers a plausible explanation for the impact I find on birth weights. Finally, columns 8 through 9 show small imprecise effects on mother's marital status and self-reported health

\footnotetext{
${ }^{18}$ The percentage effects are computed as $e^{\delta}-1$. For estimated effects on husbands' earnings over time using a similar sample from the PSID, see Lindo (2010).

${ }^{19}$ This "added worker effect" has been shown previously in Stephens (2002).

${ }^{20}$ Aizer, Stroud, and Buka (2009) speak to this issue, using within family variation to show that maternal stress is a significant predictor of child outcomes. They do not find significant impacts on birth weights, however. In contrast, Eskenazi et al. (2007) and Camacho (2008) both find that prenatal stress reduces birth weights.
} 
in the year prior to their child's birth while column 10 shows a similar effect on the probability that a child was born after a short inter-pregnancy interval, defined as less than six months between pregnancies. ${ }^{21}$

With the same caveats, Panel B interacts the indicator for a child being born after displacement with mother's education in order to shed light on the estimates from the previous section which suggest greater impacts on the birth weight of children born to more highly educated mothers. While column 1 indicates that the impact on husbands' pre-birth earnings is similar for children born to mothers with less than or equal to a high school education and mothers with more education, column 2 suggests that the impact on pre-birth family income is greater for women with more than a high school education. The point estimates imply that the effect on pre-birth family income is minimal for women with lower education (negative 3.4 percent) whereas it is substantial for women with higher levels of education (negative 18.2 percent). Columns 5 and 6 help to explain this difference, suggesting a strong positive impact on women's work activity in the year prior to birth for women with lower levels of education. In contrast, the point estimates reveal no evidence of an impact on pre-birth work activity for women with more than a high school education. Finally, column 7 suggests that the impact on pre-birth food expenditures is greater for those with less than a high school education although one cannot know whether this implies a greater impact on their nutrition.

Collectively, the set of estimates presented in Table 5 suggests that a husband's job loss has large effects on pre-birth incomes. That there seem to be small impacts on infant health for women with lower levels of education who increase their work activity to mitigate the income shock is enlightening. It suggests that the lost income itself is an important mechanism and casts doubt on the hypothesis that adverse health effects are driven by workinduced stress. While imprecise, estimated effects on food expenditures tend to be large,

\footnotetext{
${ }^{21}$ Clearly this indicator variable will equal zero for all first-born children.
} 
offering a plausible mechanism linking the income shock to the impacts on birth weights.

\section{Discussion}

As a whole, the analysis of husband's displacements reveal that this income shock negatively affects birth weights. The point estimates indicate that a husband's displacement reduces a child's birth weight by $4.5 \%$ (approximately 5 ounces) on average. To put this magnitude into context, Almond, Chay, and Lee (2004) find that smoking reduces a child's birth weight by 7.1 ounces on average. My analysis of family circumstances when children are born provide suggestive evidence that the adverse effects on infant health might be related to impacts on maternal nutrition, which is consistent with a large body of prior research.

If we assume that husbands' job losses only affect birth weights through their effects on family income in the year prior to birth, then my estimates imply an elasticity of 0.26 . This would suggest that cross-sectional comparisons, such the estimates shown in Table 6 which regresses birth weights on family incomes, understate the importance of family income as they imply an elasticity of 0.034 .

On the other hand, it is important to keep in mind that I am considering the effect of a negative income shock which might have more severe consequences than low income by itself. It is also important to note that, while the most salient feature of a husband's displacement is its large and permanent impact on family income, the impact on birth weights might be generated by aspects of the shock other than the loss of income. For example, a husband's

job loss may might reduce birth weights because of its impact on stress. At the same time, if the reason that stress increases is because of the lost income, then we would still be correct in interpreting the estimated effects as resulting from the income shock. 


\section{Conclusion}

In this paper, I have examined the impacts of husbands' job displacements on children's birth weights. My findings represent a nice parallel with Sullivan and von Wachter (2009). Whereas there is evidence that mortality improves during recessions (Ruhm 2000), Sullivan and von Wachter (2009) show that individuals' job losses increase their mortality. Similarly, while Dehejia and Lleras-Muney (2004) present convincing evidence that birth weights improve during recessions, I find that husbands' job displacements have a negative effect on birth weights.

Although these results chip away at the "why do birth weights improve during recessions?" question, much work remains to be done on this topic. My results indicate that some aspects of adverse macroeconomic conditions besides husbands' job losses must play a major role. In fact, these other aspects must play a role so great that they more than offset the negative consequences of husbands' job losses that I find. What might these things be? Dehejia and Lleras-Muney (2004) show that there is positive selection into motherhood during recessions. That is, that women who have children during recessions are the types who would always tend to have healthier children. Another possible explanation relates to work-induced stress. Specifically, infant health might improve during recessions because women are less likely to be working while pregnant.

The results of this paper also shed light on the relationship between socioeconomic status and health. Like prior papers, one could think of the displacement as a plausibly exogenous shock to household income. In that sense, my results suggest that the positive cross-sectional relationship between income and infant health is indicative of the causal link. This in turn implies that policies that provide income support, in addition to increasing consumption, can be expected to have the additional benefit of improving health outcomes. 


\section{References}

Aizer, A., L. Stroud, and S. Buka (2009): "Maternal Stress and Child Well-Being: Evidence from Siblings," Mimeo.

Almond, D., K. Y. Chay, and D. S. Lee (2005): "The Costs of Low Birth Weight," Quarterly Journal of Economics, 120(3), 1031-1083.

Almond, D., H. W. Hoynes, and D. W. Schanzenbach (Forthcoming): "Inside the War on Poverty: The Impact of Food Stamps on Birth Outcomes," Review of Economics and Statistics.

Almond, D., And B. Mazumder (2008): "Health Capital and the Prenatal Environment: The Effect of Maternal Fasting During Pregnancy," NBER Working Paper No. 14428.

Behrman, J. R., and M. R. Rosenzweig (2004): "Returns to Birthweight," The Review of Economics and Statistics, 86(2), 586-601.

Bitler, M. P., And J. Currie (2004): "Does WIC Work? The Effects of WIC on Pregnancy and Birth Outcomes," Journal of Policy Analysis and Management, 23(4), $73-91$.

Black, S. E., P. J. Devereux, and K. G. Salvanes (2007): "From the Cradle to the Labor Market? The Effect of Birth Weight on Adult Outcomes," Quarterly Journal of Economics, 122(1), 409-439.

Browning, M., A. M. Dano, and E. Heinesen (2006): "Job Displacement and StressRelated Health Outcomes," Health Economics, 15(10), 1061-1075.

Burlando, A. (2010): "When the Lights Go Out: Permanent Health Effects of Transitory Shocks," Mimeo.

Camacho, A. (2008): "Stress and Birth Weight: Evidence from Terrorist Attacks," American Economic Review Papers and Proceedings, 98(2), 511-515.

Charles, K. K., and M. Stephens Jr. (2004): "Job Displacement, Disability, and Divorce," Journal of Labor Economics, 22(2), 489-522.

Currie, J., and E. Moretti (2007): "Biology as Destiny? Short- and Long-Run Determinants of Intergenerational Transmission of Birth Weight," Journal of Labor Economics, 25(2), 231-263.

Dehejia, R., and A. Lleras-Muney (2004): "Booms, Busts, and Babies' Health," Quarterly Journal of Economics, 119(3), 1091-1130.

Eliason, M., and D. Storrie (2009): "Does Job Loss Shorten Life?," Journal of Human Resources, 44(2), 227-302. 
Eskenazi, B., A. R. Marks, R. Catalano, T. Bruckner, and P. G. Toniolo (2007): "Low birthweight in New York city and upstate New York following the events of September 11th," Human Reproduction, 22(11), 3013-3020.

Hoynes, H. W., M. E. Page, and A. H. Stevens (2009): "Is A WIC Start a Better Start? Evaluating WIC's Impact on Infant Health Using Program Introduction," NBER Working Paper No. 15589.

Jacobson, L. S., R. J. LaLonde, and D. G. Sullivan (1993): "Earnings losses of displaced workers," American Economic Review, 83(4), 685-709.

Johnson, R. C., And R. F. Schoeni (2007): "Early-Life Origins of Adult Disease: The Significance of Poor Infant Health and Childhood Poverty," PSC Research Report No. 07-616.

Kuhn, A., R. Lalive, and J. Zweimüller (2007): "The Public Health Costs of Unemployment," Cahiers de Recherches Economiques du Dpartement d'Economtrie et d'Economie politique (DEEP) 07.08, Universit de Lausanne, Facult des HEC, DEEP.

Lindahl, M. (2005): "Estimating the Effect of Income on Health and Mortality using Lottery Prizes as Exogenous Source of Variation in Income," Journal of Human Resources, 40(1), 144-168.

Lindo, J. M. (2010): "Are Children Really Inferior Goods? Evidence from Displacementdriven Income Shocks," Journal of Human Resources, 45(2), 301-327.

Martikainen, P., N. Maki, and M. Jantti (2007): "The Effects of Unemployment on Mortality following Workplace Downsizing and Workplace Closure: A Register-based Follow-up Study of Finnish Men and Women during Economic Boom and Recession.," American Journal of Epidemiology, 165(9), 1070-1075.

Oreopoulos, P., M. Page, and A. H. Stevens (2008): "The Intergenerational Effects of Worker Displacement," Journal of Labor Economics, 26(3), 455-483.

Oreopoulos, P., M. Stabile, R. Walld, and L. Roos (2008): "Short, Medium, and Long Term Consequences of Poor Infant Health: An Analysis using Siblings and Twins," Journal of Human Resources, 43(1), 88-138.

Page, M., A. H. Stevens, and J. M. Lindo (2009): "Parental Income Shocks and Outcomes of Disadvantaged Youth in the United States," in An Economic Perspective on the Problems of Disadvantaged Youth, ed. by J. Gruber, pp. 213-235. University of Chicago Press, Chicago.

Rege, M., K. Telle, and M. Votruba (2009): "The Effect of Plant Downsizing on Disability Pension Utilization," Journal of European Economic Association, 35(2), 754785 . 
Royer, H. (2009): "Separated at Girth: US Twin Estimates of the Long-Run and Intergenerational Effects of Fetal Nutrients," American Economic Journal: Applied Economics, $1(1), 49-85$.

Ruhm, C. J. (1991): "Are Workers Permanently Scarred by Job Displacements?," The American Economic Review, 81(1), 319-324.

- (2000): "Are Recessions Good for Your Health?," Quarterly Journal of Economics, $115(2), 617-650$.

Salm, M. (2009): "Does job loss cause ill health?," Health Economics, 18(9), 1075-1089.

Stephens JR., M. (2002): "Worker Displacement and the Added Worker Effect," Journal of Labor Economics, 20(3), 504-536.

Stevens, A. H. (1997): "Persistent Effects of Job Displacement: The Importance of Multiple Job Losses," Journal of Labor Economics, 15(1), 165-188.

Stevens, A. H., and J. Schaller (2009): "Short-run Effects of Parental Job Loss on Childrens Academic Achievement," Mimeo.

Sullivan, D., And T. von Wachter (2009): "Job Displacements and Mortality: An Analysis using Administrative Data," Quarterly Journal of Economics, 124(3), 1265-1306.

Topel, R. (1990): "Specific capital and unemployment: Measuring the costs and consequences of job loss," Carnegie-Rochester Conference Series on Public Policy, 33, 181-214. 
Figure 1

Income and Birth Weights

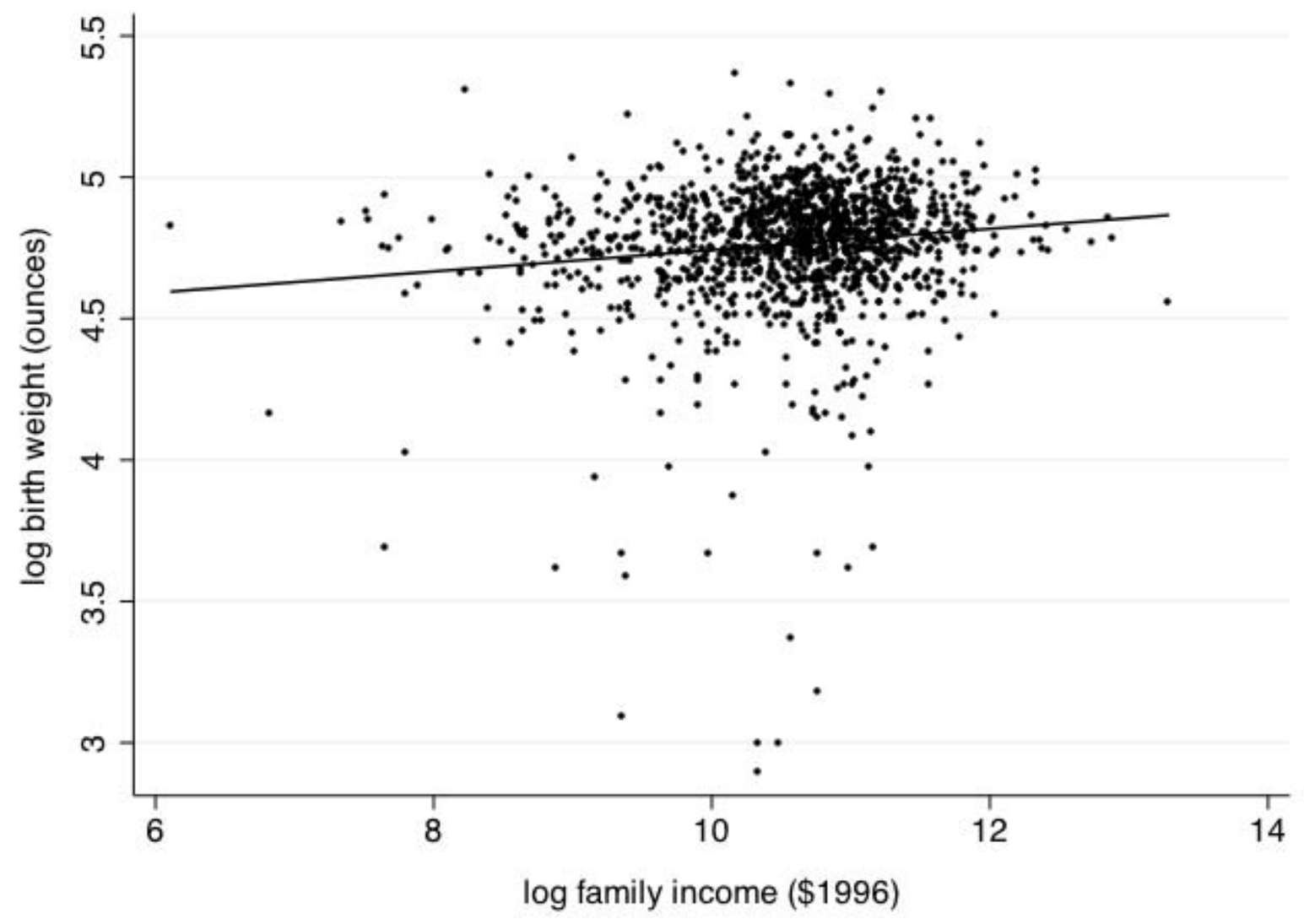

Notes: Data is from the PSID. The collection of dots represent the 1,610 births for which income is not missing in the year before the birth. The fitted line has a slope coefficient of 0.030 with a standard error estimate, clustered on the mother, of 0.015 . 
Figure 2

The Distributional Impact of a Husband's Displacement on Birth Weights

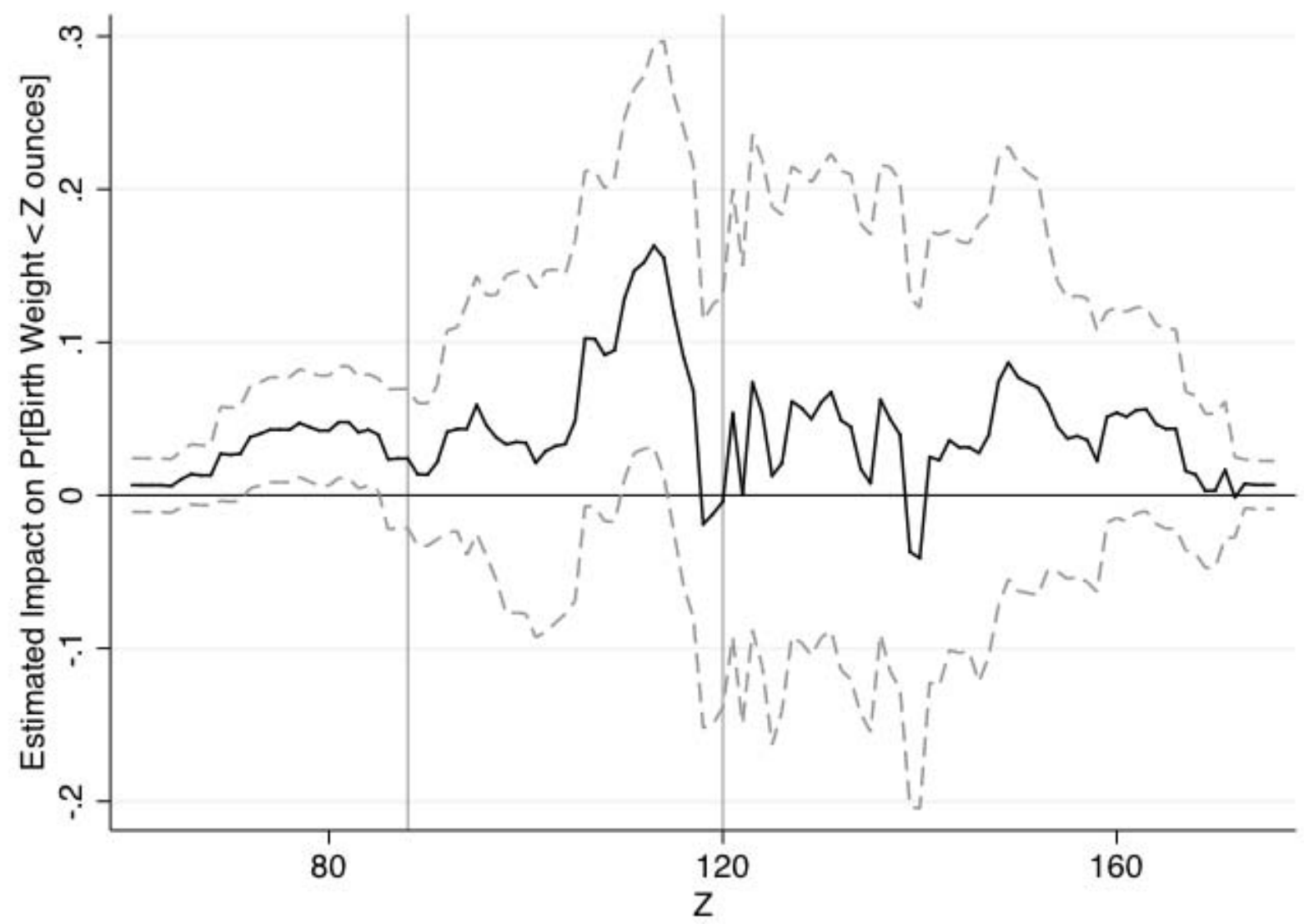

Notes: Data is from the PSID. This figure summarizes the results of over 100 regressions in which the dependent variable is an indicator variable taking one if a child's birth weight is less than $\mathrm{Z}$ ounces where $\mathrm{Z}$ is plotted on the horizontal axis. The regressor of interest is an indicator variable that takes a one if a child is born following a displacement. The estimated coefficients on this regressor are plotted in the figure along with the $95 \%$ confidence intervals. The regressions also include mother fixed effects in addition to controls for the mother's age, the year the child is born, sex, birth order, education group trends, and industry trends. Standard errors are clustered on the mother. Regressions are weighted by using children's sample weights. Vertical lines are drawn the conventional cutoff for low birth weight (88 ounces) and at the median birth weight (120 ounces). 
Table 1

Summary Statistics By Husband's Displacement Status

\begin{tabular}{lccc}
\hline & Never & Born before & Born after \\
Mother characteristics: & & & \\
S High School Education & 0.31 & 0.35 & 0.40 \\
Some college & 0.30 & 0.28 & 0.31 \\
College degree & 0.39 & 0.37 & 0.29 \\
White & 0.93 & 0.90 & 0.93 \\
Black & 0.07 & 0.10 & 0.07 \\
Age when first married & 23.2 & 22.9 & 22.1 \\
Age at first birth & 25.4 & 24.6 & 24.0 \\
& & & \\
Child-specific characteristics at birth: & 28.7 & 26.9 & 28.2 \\
Mother's Age & 1991 & 1989 & 1990 \\
Year & 2.1 & 1.8 & 2.3 \\
Birth order & 42,911 & 31,060 & 29,793 \\
Husband's Earnings (\$1996) & 62,088 & 49,084 & 47,429 \\
Parental Income (\$1996) & 0.50 & 0.53 & 0.52 \\
male & 119.7 & 128.6 & 122.12 \\
Birth weight (ounces) & 0.06 & 0.02 & 0.03 \\
Low birth weight (<88 ounces) & & & \\
Sample Size & 1,768 & 237 & 807 \\
\hline
\end{tabular}

Means are calculated using children's sample weights. The three columns are mutually exclusive from one another. In order, these columns demonstrate the means for children who are born to a mother who never experiences a husband's displacement, children born before their mother has a displaced husband, and children born following the displacement of a mother's husband. 
Table 2

Estimated Impact of a Husband's Displacement on Log Birth Weight

\begin{tabular}{lccccc}
\hline & $(1)$ & $(2)$ & $(3)$ & $(4)$ & $(5)$ \\
\hline Born after a displacement & 0.017 & $-0.041^{*}$ & $-0.047^{* *}$ & $-0.045^{*}$ & $-0.047^{*}$ \\
& $(0.015)$ & $(0.023)$ & $(0.023)$ & $(0.024)$ & $(0.025)$ \\
Child observations & 1,654 & 1,654 & 1,654 & 1,633 & 1,597 \\
Mothers & 743 & 743 & 743 & 739 & 724 \\
Individual fixed effects & no & yes & yes & yes & yes \\
Child-specific controls & no & no & yes & yes & yes \\
Education group trends & no & no & no & yes & yes \\
Industry trends & no & no & no & no & yes \\
\hline
\end{tabular}

Notes: All regressions include mother's age fixed effects and a polynomial in the year. Child-specific controls include sex and birth order fixed effects. Standard errors are clustered on the mother. Regressions are weighted using children's sample weights.

* significant at $10 \%$;* significant at $5 \%$;** significant at $1 \%$ 
Table 3

Estimated Impact of a Husband's Displacement on the Probability of Low Birth Weight

\begin{tabular}{lccccc}
\hline & $(1)$ & $(2)$ & $(3)$ & $(4)$ & $(5)$ \\
\hline Born after a displacement & $-0.023^{*}$ & 0.014 & 0.018 & 0.018 & 0.024 \\
& $(0.012)$ & $(0.023)$ & $(0.024)$ & $(0.024)$ & $(0.023)$ \\
Child observations & 1,654 & 1,654 & 1,654 & 1,633 & 1,597 \\
Mothers & 743 & 743 & 743 & 739 & 724 \\
Individual fixed effects & no & yes & yes & yes & yes \\
Child-specific controls & no & no & yes & yes & yes \\
Education group trends & no & no & no & yes & yes \\
Industry trends & no & no & no & no & yes \\
\hline
\end{tabular}

Notes: Same as Table 2.

* significant at 10\%; ** significant at 5\%; *** significant at $1 \%$ 
Table 4

Estimated Impact of a Husband's Displacement on Log Birth Weight

By Timing of Birth, Child Gender, and Mother's Education

\begin{tabular}{|c|c|c|c|c|}
\hline & (1) & $(2)$ & (3) & (4) \\
\hline Born 1-2 years prior to displacement & $\begin{array}{c}-0.014 \\
(0.030)\end{array}$ & & & \\
\hline Born in year of displacement & $\begin{array}{r}-0.076^{*} \\
(0.040)\end{array}$ & & & \\
\hline Born 1-4 years following displacement & $\begin{array}{l}-0.049 \\
(0.041)\end{array}$ & & & \\
\hline Born $5+$ years following displacement & $\begin{aligned}-0.088^{*} \\
(0.050)\end{aligned}$ & & & \\
\hline Born after layoff/fire & & $\begin{array}{l}-0.042 \\
(0.028)\end{array}$ & & \\
\hline Born after plant/business closure & & $\begin{array}{l}-0.064 \\
(0.049)\end{array}$ & & \\
\hline Born after displacement $\times$ Male & & & $\begin{array}{l}-0.031 \\
(0.030)\end{array}$ & \\
\hline Born after displacement $\times$ Female & & & $\begin{array}{c}-0.060^{* *} \\
(0.027)\end{array}$ & \\
\hline Born after displacement $\times$ Mother's Education $\leq$ HS & & & & $\begin{array}{l}-0.011 \\
(0.038)\end{array}$ \\
\hline Born after displacement $\times$ Mother's Education $>$ HS & & & & $\begin{array}{c}-0.067^{* *} \\
(0.032)\end{array}$ \\
\hline Child Observations & 1,597 & 1,597 & 1,597 & 1,597 \\
\hline Mothers & 724 & 724 & 724 & 724 \\
\hline Individual fixed effects & yes & yes & yes & yes \\
\hline Child-specific controls & yes & yes & yes & yes \\
\hline Education group trends & yes & yes & yes & yes \\
\hline Industry trends & yes & yes & yes & yes \\
\hline
\end{tabular}

Notes: Same as Table 2.

* significant at 10\%; ** significant at 5\%; *** significant at $1 \%$ 


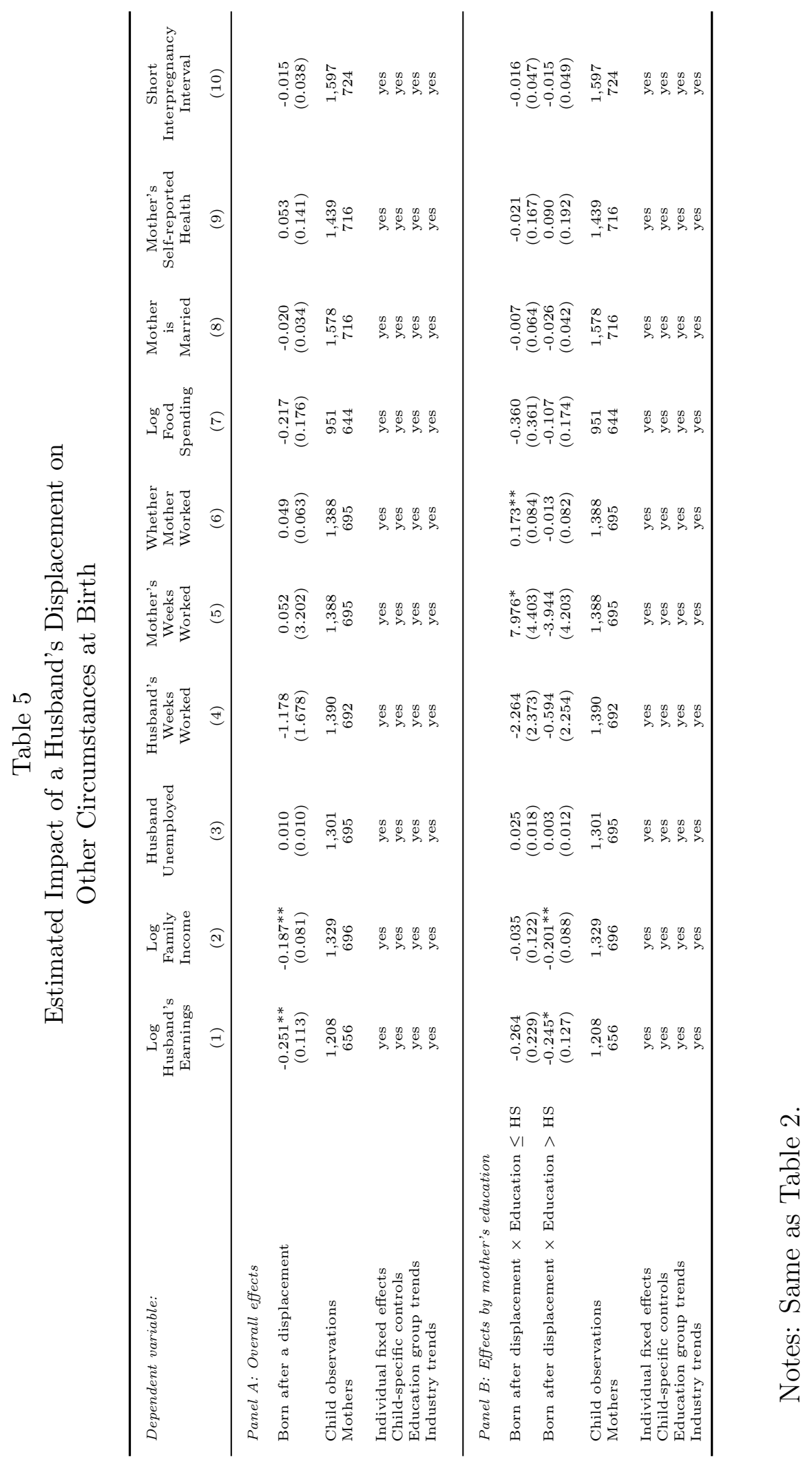


Table 6

Family Income and Birth Weights

\begin{tabular}{lcccccc}
\hline Dependent variable: & \multicolumn{2}{c}{ Ln birth weight } & & \multicolumn{2}{c}{ Weight $<88$ ounces } \\
\cline { 2 - 3 } \cline { 6 - 7 } & $(1)$ & $(2)$ & & $(3)$ & $(4)$ \\
\hline Log Family Income & $0.030^{* *}$ & $0.034^{* *}$ & & $-0.024^{* *}$ & -0.026 \\
& $(0.015)$ & $(0.021)$ & & $(0.012)$ & $(0.016)$ \\
Child observations & 1364 & 1356 & & 1364 & 1356 \\
Mothers & 715 & 710 & & 715 & 710 \\
Additional controls & no & yes & & no & yes \\
\hline
\end{tabular}

Notes: Additional controls include year fixed effects and mother's age fixed effects. Standard errors are clustered on the mother. Regressions are weighted using children's sample weights.

* significant at $10 \% ; * *$ significant at $5 \%$; *** significant at $1 \%$ 
Table A1

Distribution of Birth Weights in Analysis Sample Versus 1990 Vital Statistics

\begin{tabular}{lcc}
\hline & $\begin{array}{c}\text { Fraction in } \\
\text { Analysis Sample }\end{array}$ & $\begin{array}{c}\text { Fraction in } \\
\text { 1990 Vital Statistics }\end{array}$ \\
\hline Birth Weight $<18$ ounces & 0.00 & 0.00 \\
Birth Weight $<35$ ounces & 0.00 & 0.01 \\
Birth Weight $<53$ ounces & 0.01 & 0.01 \\
Birth Weight $<71$ ounces & 0.03 & 0.03 \\
Birth Weight $<88$ ounces & 0.06 & 0.07 \\
Birth Weight $<106$ ounces & 0.22 & 0.23 \\
Birth Weight $<123$ ounces & 0.55 & 0.60 \\
Birth Weight $<141$ ounces & 0.85 & 0.89 \\
Birth Weight $<159$ ounces & 0.97 & 0.98 \\
Birth Weight $<176$ ounces & 0.99 & 1.00 \\
\hline
\end{tabular}

Note: Birth weights in the Vital Statistics are actually reported in grams. Their categories (in 500s of grams) have been converted and rounded to ounces to be consistent with the units used to measure birth weights in the PSID. 1990 is chosen as the comparison year because it is the median year of birth for the analysis sample. 
Table A2

Estimated Impact of a Husband's Displacements Due to Plant/Business Closures on the Birth Weight

\begin{tabular}{|c|c|c|c|c|c|}
\hline & $(1)$ & $(2)$ & $(3)$ & $(4)$ & $(5)$ \\
\hline \multicolumn{6}{|c|}{ Dependent Variable: Log Birth Weight } \\
\hline Born after a displacement & $\begin{array}{c}0.014 \\
(0.023)\end{array}$ & $\begin{array}{l}-0.056 \\
(0.045)\end{array}$ & $\begin{array}{l}-0.064 \\
(0.049)\end{array}$ & $\begin{array}{c}-0.062 \\
(0.049)\end{array}$ & $\begin{array}{l}-0.077 \\
(0.049)\end{array}$ \\
\hline Child observations & 1,654 & 1,654 & 1,654 & 1,633 & 1,597 \\
\hline Mothers & 743 & 743 & 743 & 739 & 724 \\
\hline Individual fixed effects & no & yes & yes & yes & yes \\
\hline Child-specific controls & no & no & yes & yes & yes \\
\hline Education group trends & no & no & no & yes & yes \\
\hline Industry trends & no & no & no & no & yes \\
\hline \multicolumn{6}{|c|}{ Dependent Variable: Probability of Low Birth Weight } \\
\hline Born after a displacement & $\begin{array}{c}-0.009 \\
(0.021)\end{array}$ & $\begin{array}{l}-0.016 \\
(0.021)\end{array}$ & $\begin{array}{l}-0.005 \\
(0.025)\end{array}$ & $\begin{array}{l}-0.004 \\
(0.024)\end{array}$ & $\begin{array}{c}0.012 \\
(0.026)\end{array}$ \\
\hline Child observations & 1,654 & 1,654 & 1,654 & 1,633 & 1,597 \\
\hline Mothers & 743 & 743 & 743 & 739 & 724 \\
\hline Individual fixed effects & no & yes & yes & yes & yes \\
\hline Child-specific controls & no & no & yes & yes & yes \\
\hline Education group trends & no & no & no & yes & yes \\
\hline Industry trends & no & no & no & no & yes \\
\hline
\end{tabular}

Notes: Same as Table 2.

* significant at 10\%; ** significant at 5\%; *** significant at $1 \%$ 